\title{
O papel do HNF4 na regeneração da massa secretora de insulina
}

\author{
Chelsy C. Ifekaibeya (IC), Gustavo J. Santos (PQ), Antonio C. Boschero (Orientador) \\ Depto de Biologia Estrutural e Funcional/IB/Unicamp
}

\section{Resumo}

O Diabetes Mellitus (DM) é uma síndrome metabólica caracterizada pela hiperglicemia e por alterações no metabolismo de diversos nutrientes, resultante tanto da ausência de insulina, em decorrência da depleção total das células beta pancreáticas (DM1), quanto da incapacidade da insulina em realizar suas funções corretamente (DM2). Nas células beta há um importante fator de transcrição nuclear, o HNF4a, que atua no controle do aumento da massa dessas células. Com isso, objetivaremos avaliar esta função do HNF4a, bem como a sua participação na restauração das células beta em animais diabéticos por streptozotocina.

Palavras Chave: Células beta, HNF4a, Diabetes

\section{Introdução}

O Diabetes Mellitus (DM) é uma doença crônica, caracterizada por alterações no metabolismo intermediário, decorrente tanto da ausência de insulina (DM1) quanto da incapacidade deste hormônio em realizar suas funções corretamente (DM2). O desenvolvimento do DM1 pode estar relacionado à distúrbios autoimunes que causam a destruição das células beta pelos autoanticorpos, que por não as reconhecerem passam a atacá-las. A perda destas células leva a diminuição da produção de insulina, fato que reflete no aumento da concentração de glicose na corrente sanguínea, caracterizando, assim, a hiperglicemia. Hoje, o foco de muitas pesquisas está na regeneração de células secretoras de insulina, a fim de restaurar a glicemia do indivíduo. O HNF4a é um fator de transcrição responsável por diversos processos em vários tipos celulares, estando nas células beta envolvido com processos de secreção de insulina e de controle da massa secretora. Com isso, buscaremos avaliar o papel do HNF4a na regeneração de célula beta após a instauração de DM1 em animais expostos a uma droga diabetogênica, a Streptozotocina (STZ).

\section{Resultados e Discussão}

A Figura 1 nos mostra que os animais que receberam a streptozotocina apresentaram menor marcação para a insulina, indicando que a ação da droga em destruir as células produtoras de insulina foi eficiente. No dia 3 observa-se grande destruição da massa de célula beta que, ao longo do tempo é em parte recuperada. Essa recuperação fica evidente nos dias 14 e 21, nos quais observamos um aumento na marcação para a insulina. Concomitantemente, avaliamos a marcação para o Ki67. Com a destruição da massa das células beta, observamos um aumento na proliferação das células da ilhota. Esse fato é melhor observado quando olhado nos dias 7 e 14.
De maneira a relacionar, observamos maior marcação do Ki67 nos dias 7 e 14 e para insulina nos dias 14 e 21, indicando que o aumento da proliferação pode estar relacionado com 0 aumento da proliferação das células beta.

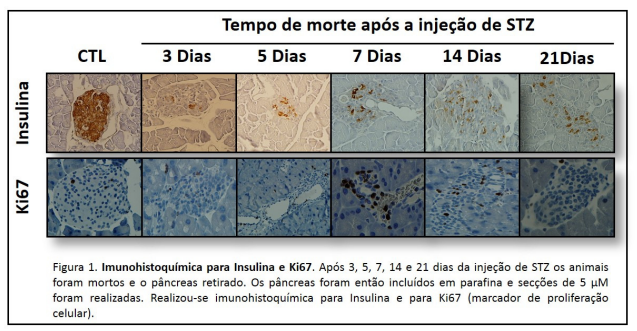

Conclusões

Observamos que com o tempo, de forma espontânea, a massa de célula beta foi recuperada, acompanhada do aumento na expressão de Ki67 (Figura 1). Isso nos mostra que a célula beta tem a capacidade de se regenerar e, como próximos passos, avaliaremos quais células da ilhota apresentam maior expressão de Ki67 e qual foi o papel do HNF4a nesse processo.

\section{Agradecimentos}

Ao Prof. Dr. Antonio Carlos Boschero por ter me aceitado como orientanda de um projeto tão importante como este, ao Gustavo Jorge dos Santos por todo auxílio, dedicação e confiança depositados em mim e, por fim, à minha família por todo apoio dado durante este ano.

\footnotetext{
1 SANTOS, G. O papel do HNF4a na manutenção da massa funcional das células $\beta$ pancreáticas em animais resistentes à insulina ou diabéticos por Streptozotocina (STZ). Universidade Estadual de Campinas. São Paulo. Projeto de pós doutorado 2013. LEE, S.H. , PIRAN, R. , KEINAN. E. , PINKERTON, A. LEVINE, F. : Induction of beta-cell Replication by a Synthetic HNF4 $\alpha$ Antagonist. Stem Cells 2013:31:2396-2407
} 